\title{
Low back pain and gastroesophageal reflux in patients with COPD: the disease in the breath
}

This article was published in the following Dove Press journal: International Journal of COPD

\author{
Bruno Bordoni' \\ Fabiola Marelli ${ }^{2,3}$ \\ Bruno Morabito 2,3 \\ Beatrice Sacconi ${ }^{4,5}$ \\ Philippe Caiazzo ${ }^{6}$ \\ Roberto Castagna ${ }^{2}$
}

'Foundation Don Carlo Gnocchi IRCCS, Department of Cardiology, Scientific Institute of Hospitalization and Care, Milan, ${ }^{2}$ Department of Fascial Osteopathic Research, CRESO, School of Osteopathic Centre for Research and Studies, Gorla Minore, ${ }^{3}$ Department of Fascial Osteopathic Research, CRESO, School of Osteopathic Centre for Research and Studies, Fano, ${ }^{4}$ Department of Radiological, Oncological and Anatomopathological Sciences, Sapienza University of Rome, ${ }^{5}$ Department of Radiological, Oncological and Anatomopathological Sciences, Center for Life Nano Science@Sapienza, Istituto Italiano di Tecnologia, Rome, 'Department of Osteopathic Research, AITOP, Italian Academy of Postural Osteopathic Therapy, Levizzano Rangone Castelvetro, Italy
Correspondence: Bruno Bordoni Foundation Don Carlo Gnocchi IRCCS, Department of Cardiology, Scientific Institute of Hospitalization and Care, S Maria Nascente, Via Capecelatro 66, Milan 20100, Italy

Tel +39023496300617

Email bordonibruno@hotmail.com

\begin{abstract}
COPD is a worsening condition that leads to a pathologic degeneration of the respiratory system. It represents one of the most important causes of mortality and morbidity in the world, and it is characterized by the presence of associated comorbidity. This article analyzes gastroesophageal reflux disease (GERD) and low back pain (LBP) in patients with COPD and tries to produce anatomo-clinical considerations on the reasons of the presence of these comorbidities. The considerations of the authors are based on the anatomic functions and characteristics of the respiratory diaphragm that are not always considered, from which elements useful to comprehend the symptomatic status of the patient can be deduced, finally improving the therapeutic approach. The information contained in the article can be of help to the clinician and for physiotherapy, and to all health professionals who gravitate around the patient's care, improving the approach to the diaphragm muscle.
\end{abstract}

Keywords: COPD, diaphragm, low back pain, GERD, fascia

\section{Introduction}

COPD is a worsening and chronic condition that leads to a pathologic degeneration of the respiratory system. It represents one of the most important causes of mortality and morbidity in the world and is characterized by the presence of many associated comorbidities.

Relapses of the disease during the life of the patient and the comorbidity impoverish clinical results, lengthening the time of hospitalization and worsening the quality of life (QOL). ${ }^{1}$ It is reported that between $51 \%$ and $88 \%$ of patients with COPD have at least one comorbidity such as, for example, cardiovascular pathologies, arthritis, osteoporosis, diabetes and chronic pain. ${ }^{1,2}$

The mechanisms that cause these comorbidities and the precise relation with the presence of COPD are not entirely clear. ${ }^{3}$

Probably, the systemic inflammatory nature of the disease favors the natural course of these comorbidities, which reflect the systemic roots of COPD. ${ }^{3}$

Gastroesophageal reflux disease (GERD) is a comorbidity often found in patients. It has the potential of exacerbating the symptoms, increasing the number of events of hospitalization. ${ }^{3}$

The prevalence of GERD varies between $7.7 \%$ and $37 \%$, of which $58 \%$ of the cases are asymptomatic. ${ }^{3,4}$

Nonspecific low back pain (LBP) is another comorbidity present in patients with COPD, with a percentage that varies between $41.2 \%$ and $69 \%{ }^{2,5}$ The percentages of LBP are similar to the ones of a population in the absence of respiratory pathologies, but the level of pain registered in the presence of COPD is higher. ${ }^{2}$ 
At the moment, there is no direct relation recognized as absolutely valid that could explain the presence of GERD, LBP and COPD. ${ }^{2,5}$ In the scientific landscape, we do not have enough information to correlate the function of the diaphragm in patients with COPD and such a comorbidity. As described subsequently, we have a lot of information on dysfunction of the respiratory muscle. This article analyzes GERD and LBP in patients with COPD and tries to produce anatomo-clinical considerations on the reasons of the presence of these comorbidities and dysfunction of the diaphragm (Figure 1). The considerations of the authors are based on the anatomic functions and characteristics of the respiratory diaphragm not always considered, from which elements useful to comprehend the symptomatic status of the patient can be deduced. The article can be of help to better understand the functioning of the diaphragm muscle, helping the clinician, physiotherapist and osteopath for the rehabilitative organization.

The text represents the first step in a series of other articles, where it will try to decipher the causes of other comorbidities, associating them with the presence of diaphragmatic dysfunction.

\section{GERD and COPD}

The esophagogastric junction (EGJ) is a mutual collaboration among different anatomic parts to allow the correct functioning between the esophagus, the diaphragm and the stomach. It consists of the esophagus that crosses the diaphragmatic hiatus to reach the stomach. In EGJ, we can identify the lower esophageal sphincter (LES), the diaphragmatic hiatus and the gastric cardia, which constitute the distal part of the EGJ high-pressure zone. ${ }^{6}$ LES is a segment of 3-4 cm constituted by smooth muscle; its tone in relation to the intragastric pressure in healthy individuals is $10-30 \mathrm{mmHg}^{6}$

Throughout the day, LES endures large pressure variations managed by a complex neurologic mechanism, which involves the central nervous system, and the enteric, sympathetic and vagal systems.

We observe vagal afferences and sympathetic/vagal efferences; vagal efferences are mediated by the neurons of the myenteric plexus through cholinergic synapses. ${ }^{6}$

These transient relaxations of the tone of LES can be noticed in healthy individuals and in patients with GERD. Its mechanism is stimulated by the vagal afferences of the gastric cardia. The most important trigger of this mechanism
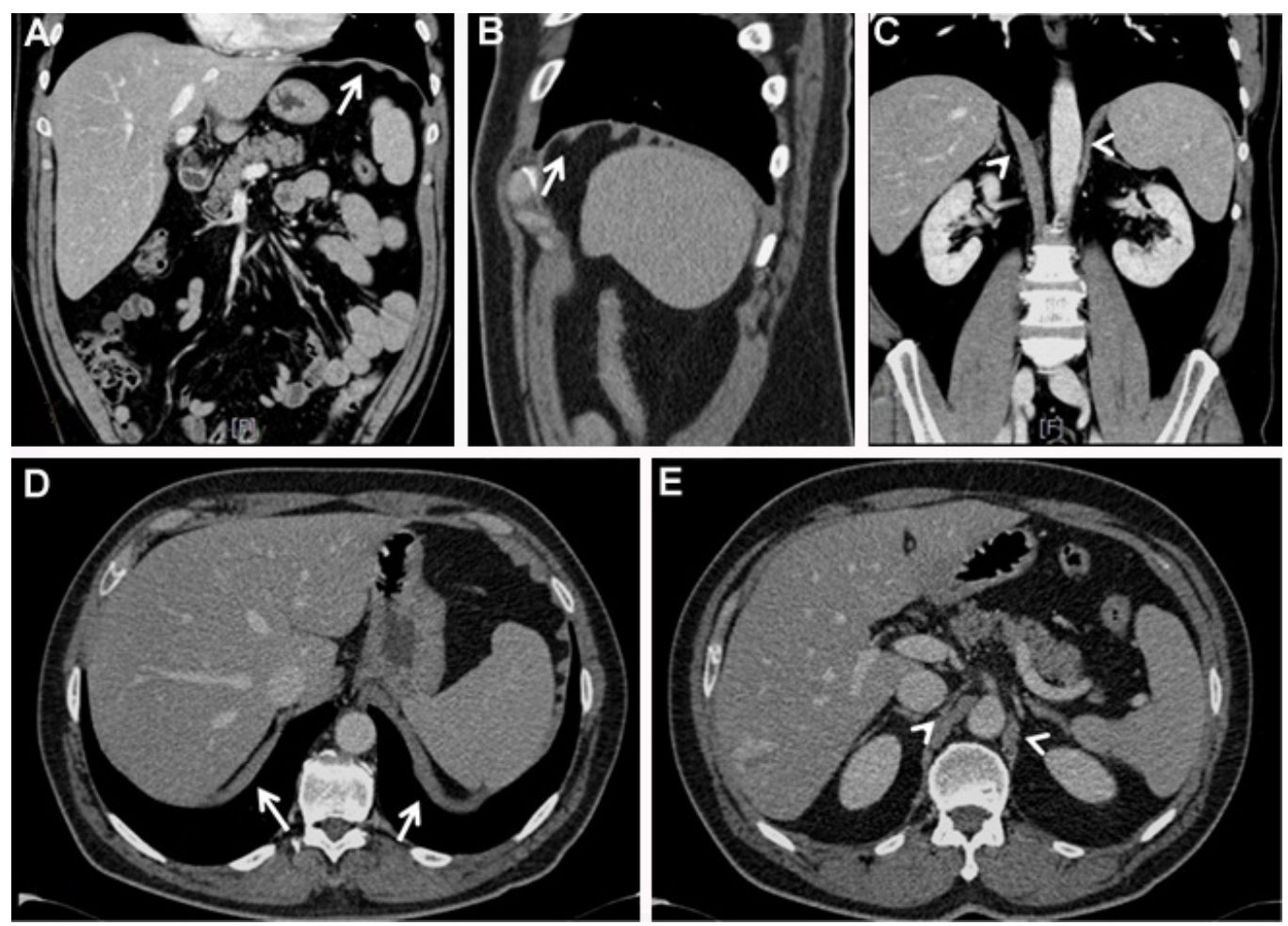

Figure I CT images.

Notes: The CT images in the coronal and axial planes allow visualization of the diaphragm as a hyperdense linear band interposed between the chest and the abdominal cavity (A and D, respectively; see arrows). Sagittal images highlight a sort of "corrugated" morphology that shows the orientation of the muscle bundles (B; see arrow), which may appear more or less pronounced in wellness or pathologic conditions, such as COPD. Clearly visible diaphragmatic pillars also appear in both the coronal plane (C) and the axial plane (E) (arrowheads).

Abbreviation: CT, computed tomography. 
is gastric distension. This way, the dorsal motor neurons of the vagal nuclei are stimulated. Their efferences relax the tone of LES, while the esophagus shortens and the diaphragmatic hiatus is inhibited. ${ }^{7}$ This relaxation stimulates the GERD.

The frequency of this mechanism is similar between healthy individuals and patients with GERD; the difference stands in the quantity of reflux, which doubles in patients with GERD. ${ }^{7}$

The gastric cardia, where the side wall of the esophagus meets the medial dome of the stomach (called angle of His), looks like a crease and facilitates an increase in intragastric pressure. ${ }^{6}$

The crura of diaphragm (that surrounds the LES) represent the extrinsic sphincter of the EGJ complex. We will better analyze the topic of the diaphragmatic area in the section dedicated to diaphragm.

The most common causes that determine the presence of GERD are hiatus hernia, positive pressure between the stomach and the esophagus, delayed gastric emptying, inadequate esophageal cleanliness (peristalsis, salivary bicarbonate) and esophageal trauma. ${ }^{7}$

Other causes can be traced back to peripheral sensitization due to the constant stimulation of inflammatory mediators (pepsin, bile, ATP, cytokines, hydrochloric acid, histamine), lowering the afferential vagal and nociceptive threshold. This reduction increases the permeability to cations of pain receptors, with the appearance of primary hyperalgesia; with time, other nociceptors are activated, such as acid-sensing ion channels, transient receptor potential V1 and P2X purinoceptors (ATP-gated ion channel). ${ }^{7}$

This scenario would lead to phenomena such as secondary hyperalgesia and allodynia, with central sensitization due to the persistent involvement of medullary neurons and cerebral areas, with the involvement of the neuropsychoimmune system. ${ }^{7}$

\section{GERD, like COPD, becomes a systemic pathology}

The reflux is a risk factor for reaggravation in patients with COPD. ${ }^{1,8,9}$

One of the causes could be traced back to silent bronchial microsuction, causing bacterial colonization and inflammatory reactions, and bronchoconstriction caused by esophagobronchial reflexes. ${ }^{9}$

Using a noninvasive method to evaluate the $\mathrm{pH}$ of breathing in patients with COPD, the exhaled breath condensate, the presence of pepsin in higher quantities than in individuals without respiratory pathologies has been demonstrated. ${ }^{10}$ Pepsin was found in the bronchi of $88 \%$ of 42 patients without COPD, but with GERD, using a bronchial lavage fluid. ${ }^{8}$ Pepsin is a gastric enzyme derived from the aspartate protease family and is secreted by the cells of the epithelium of the gastric fundus. ${ }^{8}$

The clinical difficulty in noticing GERD stands in the fact that patients often do not show the classic symptoms (heartburn or regurgitation) and can be unaware of suffering from reflux. ${ }^{3,7,11}$

This clinical deficiency leads to a further lowering of the health-related QOL, an evaluation tool to measure the QOL of patients with chronic diseases, which is already low in patients with COPD. ${ }^{12}$ The frequency scale for the symptoms of GERD (FSSG) allows to evaluate not only the usual symptoms (heartburn or regurgitation) but also the unusual ones such as gastric dysmotility (swollen stomach). ${ }^{4}$ FSSG applied to patients with asthma and COPD revealed that the most relevant symptom of patients with COPD was gastric dysmotility; the scale also highlighted a higher exacerbation of the symptoms in patients with COPD. ${ }^{4}$

One of the possible causes of these microaspirations is a pathologic alteration of the vagal laryngeal/pharyngeal reflex with diminished laryngopharyngeal mechanosensitivity. ${ }^{11}$ Another possible factor responsible for the aspiration could be traced back to the incoordination between the action of swallowing and the respiratory act. In healthy individuals, swallowing usually takes place at the end of inhalation or during exhalation, lowering the risk of inhaling solid material; furthermore, deglutition preferentially takes place when lung volumes are above the residual functional capacity. ${ }^{11}$ In patients with COPD, deglutition generally takes place during inhalation, increasing the risk of worsening the symptom picture. ${ }^{11}$

Medicines such as beta-agonist bronchodilators lower the tone of LES in patients with COPD, decreasing the function of the anti-reflux barrier. ${ }^{4,13}$ Other medicines, such as theophylline and inhaled steroids, increase the reflux, but we still do not know the exact mechanisms that regulate these processes. ${ }^{4}$

Another observation to make is the entity of hypoxia and of bronchial obstruction with the seriousness of GERD in patients with COPD. Ventilation influences the quality of the bloodstream toward the gastric mucosa and the $\mathrm{pH}$ of the mucosa. The presence of COPD has harmful effects on the integrity of the mucosa, especially if the respiratory pathology is longstanding. ${ }^{4}$ This could increase the reflux. 


\section{LBP and COPD}

LBP is the most common and painful condition one can suffer from over the course of their life; it is estimated that $84 \%$ of the world population suffers from LBP at least once. ${ }^{14}$ It is classified as acute within 6 weeks from the moment it appears, subacute between 6 and 12 weeks and chronic after the 12 th week. ${ }^{14}$ There are multiple and often concomitant causes, from the emotional sphere to the visceral and somatic sphere. Depression and anxiety caused by the pain can create a vicious circle and increase the painful sensation, causing sleep deprivation. ${ }^{15}$ LBP can develop after a previous surgery, even though the causes that produce the pain are still not completely clear. ${ }^{16}$ In some cases, the visceral sphere (viscero-somatic reflex) could be an important contributory cause for the development of LBP. ${ }^{17,18}$ The viscero-somatic reflexes that reach the nervous system through neural and humoral pathways can be subdivided into two groups. The first one concerns the visceral afferent information that leads to motivational information (satiety, nausea, thirst and so on) and respiratory sensations, traveling through the vagus nerve and the glossopharyngeal nerve, reaching the nucleus of the solitary tract, which will then project it to the hypothalamus, to the ventro-lateral medulla and the parabrachial nuclei with connections with the periaqueductal gray area, the thalamus, the amygdala, the insular cortex and other areas of the cortex. ${ }^{19}$ The second group consists of visceral afferences that project themselves on the dorsal horn, through lamina 1 , constituting the spinothalamic tract and sending information on the local organ functioning, for example, data on pain and heat. ${ }^{19}$ Lamina 1 receives information from the sympathetic system, other than from the skin and the epithelial mucosae. ${ }^{20}$ Visceral afferences tend to predominate in nerves of the parasympathetic type and are present in smaller percentages in the sympathetic system, even though they act in perfect harmony; however, visceral painful information travels through the sympathetic system. ${ }^{21}$ There are multiple main somatic causes linked to direct alterations of the vertebral structure: spinal disc herniation with the involvement of the root, spinal stenosis, spondylolisthesis, fractures, facet joint syndrome and sacroiliac joint syndrome, entrapment of the nerve in myofascial structures and myofascial syndrome. ${ }^{22}$ Alterations of the skin, such as scars of previous trauma or abdominal surgeries, could cause entrapment of the nerves, derived from the lumbar and sacral plexus, and chronic pain. ${ }^{23}$ Changes in the physiologic lumbar lordosis that persist after a pregnancy are another cause of LBP. ${ }^{24}$

The presence of pain is related to the respiratory function (forced expiratory volume in 1 second) in patients with a high percentage of localization in the lumbar area. ${ }^{25}$ The possible causes are multifactorial, and the presence of many comorbidities can exacerbate the feeling of pain. ${ }^{2}$

The percentage of osteoporosis is from two to five times higher in patients with COPD than in patients with osteoporosis, but without limitations of the air flow. ${ }^{26,27}$ LBP in this population of patients could often be related to vertebral compression due to a fracture (collapse), with a concomitant reduction of the vital capacity and the forced expiratory volume in 1 second. ${ }^{26}$ This reduction could be linked to the postural change that follows the vertebral collapse, with hyperkyphosis and reduction of lung volumes, with the progression of the disease and increase in mortality. ${ }^{26,27} \mathrm{It}$ is not easy to link LBP to COPD. In fact, even though vertebral compression is common in patients with osteoporosis and worsening respiratory disease, the collapse remains unrecognized in at least half of the patients. The lack of experience of the patients in correctly identifying lumbar pain as a fracture probably leads to nonidentification of the problem. ${ }^{27}$

Another probable cause of the presence of LBP is neuropathic pain. The cytokines produced and their activation in a systemic condition such as COPD could create the basis for chronic and neuropathic pain in patients with COPD. ${ }^{28}$ The local inflammatory response is perpetuated not only at a pulmonary level but also to distant tissues, thanks to circulation. Tumor necrosis factor-alpha has been demonstrated to stimulate the phenomenon of mechanical allodynia, lowering the threshold of the endings of the fiber of type C. ${ }^{28}$ Interleukin- $1 \mathrm{~b}$, just like interleukin-6, is considered a key cytokine to create the conditions for hyperalgesia. ${ }^{28}$ Dyspnea and pain activate common brain areas such as anterior insula and medial insula, anterior cingulate cortex, somatosensory cortex and motor cortex, amygdala and thalamus. ${ }^{28}$ Patients with chronic dyspnea and persistent stress of the mentioned brain areas could probably change some zones of pain perception, causing sensitization that could lead to allodynia and neuropathic pain. ${ }^{28}$

The previously mentioned postural change alters the muscular dynamics and the range of motion of the rib cage and the lumbar area; it limits the degrees of movement. This leads to a higher muscular fatigue for the diaphragm and the associated musculature (thorax and spine), creating an inflammatory environment and microlacerations of the contractile districts of the lumbar area. These muscles are more prone to overuse injury and with presence of delayed onset muscle soreness. ${ }^{28}$ This inflammation probably worsens the neuropathic conditions. The fear and anxiety of feeling the pain or dyspnea limits the activities of daily life, creating a vicious circle in the limitation of movement. ${ }^{28,29}$ 
The diaphragm plays a key role in lumbar posture, and its functional decline leads to LBP. ${ }^{5}$ Patients with COPD show diaphragmatic fatigue and less postural control, increasing the possibility of falling and of the development of LBP. The diaphragm looks flattened, with a less range of motion and altered breathing schemes in comparison with those of individuals without COPD. ${ }^{5}$ Hyperinflation forces the diaphragm to work more, leaving out its postural functions, thereby causing imbalances in the bodily oscillations during ambulation, with incorrect distribution of the loads on the lumbar spine and LBP. ${ }^{5,30}$ In patients with COPD, the reaction of the diaphragm to the movements of the limbs is delayed or absent in comparison with that of healthy individuals, further suggesting lumbar spinal instability and the onset of LBP. ${ }^{31}$

During the long period of administration, oral corticosteroids have been demonstrated to be a cause of LBP with vertebral fractures following osteoporosis and muscle weakness, creating a vicious circle of pain and lumbar functional impairment. ${ }^{32}$

Another trigger of LBP in patients with COPD could be pulmonary hypertension. Some patients complain of pain in the lumbar area that occurs in the presence of lumbar spinal stenosis and only at night. Lumbar stenosis is derived from congenital malformations or progressive degeneration of lumbar vertebrae. In patients with COPD, a low right ventricular capacity secondary to diastolic dysfunction or a rise of intrathoracic pressure could lead to an increase of the right atrial pressure; this would cause a rise in pressure (and volumes) of venous return. ${ }^{33}$ The increase of venous pressure has repercussions on smaller veins, stretching the epidural venous plexus near the roots, triggering nocturnal symptoms of brain ischemia. ${ }^{33}$

\section{Development of the diaphragm and its innervation}

Even though the diaphragm makes up $<5 \%$ of the total body weight, it is the most important contractile muscle, after the cardiac muscle. ${ }^{34}$

The diaphragm is derived from progenitor mesodermal cells that become myoblasts, then melt into myotubes and later into myofibers; it is highly probable that myoblasts migrate from cervical somites (region of the brachial plexus) and reach pleuroperitoneal cavities, where they radiate in a mesenchymal substrate. ${ }^{35}$ Another factor that could determine the maturation and function of the diaphragm is the phrenic nerve. The neural control of the diaphragm begins in the perinatal period, and this neural influence determines the maturation process of the myotubes into myofibers, probably thanks to electrical activity and to the neurotrophic factors transported by the nerve. ${ }^{35}$

The development of the diaphragm takes place between the 7 th and 10th weeks; other than the pleuroperitoneal cavities, we can identify the transversal septum and the dorsal mesentery of the esophagus as precursors of the muscle. ${ }^{36}$ The transversal septum is a frontal structure that becomes the central tendon; the dorsal mesentery (which contains the primary aorta, the inferior vena cava and the esophagus) becomes the posteromedial part. ${ }^{36}$ The pleuroperitoneal cavities (made up of what would be the pleural and pericardial tissue) will melt with the rest of the pre-diaphragmatic structures. ${ }^{37}$ There is a close biunivocal relation of mutual cooperation in the development of the diaphragm and the phrenic nerve; myotubes grow and develop in parallel to the phrenic axonal growth. ${ }^{38}$ During embryonal development, some phrenic pre-axons exit the cervical area and unite in one single nerve, guiding myogenic precursors toward the pleuroperitoneal cavities (pre-diaphragm); the axon of the nerve is surrounded by myoblasts. ${ }^{35}$ The nerve only starts to ramify when the structure that would become the diaphragm starts to caudally go down the enlargement of the heart and the lungs. ${ }^{38}$ The phrenic nerve influences the shape and function of the diaphragm. ${ }^{38}$ Phrenic neurons are thought to be derived from the hypaxial motor column (located at a spinal level). ${ }^{39}$

The relation between the vagus nerve and the diaphragm in their development is still obscure, and the vagus nerve has been recently found to play a role in the contractile function of the muscle. ${ }^{40-42}$

We have no data on when and how the vagus nerve penetrates the diaphragm. The vagus nerve originates from the neural crests, in particular, from somites 1-7; from these areas, enteric neurons are born as well. ${ }^{43}$ These cells probably leave the neural tube in the ventral direction, since the neurons that form for the enteric system and the peripheral nervous system start their migration in a ventral direction. ${ }^{43}$ Probably, again, vagus nerves that are located at the sides of the primitive intestine will form branches specialized for the diaphragm. It is important to highlight that the crural region of the diaphragm is derived from the mesentery of the esophagus; the same region is later innervated by the vagus nerve. ${ }^{44}$

\section{Diaphragm, GERD and new considerations}

The crural region of the diaphragm or the extrinsic sphincter of the EGJ complex is not involved in the actions of the breath, but it is influenced by crural mecharenoceptors and 
gastric distension. ${ }^{44}$ When the alimentary bolus has to enter the stomach, the crura stop their electric activity, while in the absence of alimentary bolus, they contract together with the rest of the diaphragm during respiratory acts. ${ }^{44,45}$

This short cessation probably derives from vagal afferences that specifically control the crural area, inhibiting bulbar neurons activated during respiration, and from the direct intervention of esophageal myoenteric neurons. ${ }^{44}$ The position of the diaphragm is important for the behavior of the crural area and the esophagus. During unforced inhalation, the crura becomes horizontal in comparison with the inclined starting position, with an increase in its diameter and in the diameter of the esophagus. ${ }^{46}$ If inhalation is forced, there is a shrinkage of the esophageal diameter, caused by the shrinkage of the crus itself due to the major contraction of the muscular fibers of the pillars of the diaphragm. ${ }^{46}$ The lumbar pillars are considered as important elements for an effective anti-reflux barrier; from their lumbar tendinous insertion (right and left), they go back to the diaphragm, forming an " 8 " for the passing of the aorta first and of the esophagus later. ${ }^{46,47}$ In particular, the right pillar fuses with the edge of the central tendinous part of the diaphragm. ${ }^{46}$ The back wall of the esophagus leans on the anterior and inferior surfaces of the fibers of the left pillar, while he anterior esophageal area is partially covered by a part of the right pillar; this anatomic arrangement creates a physiological costraint. ${ }^{46}$

The diaphragm of patients with COPD is generally more horizontal, with shorter inhalations and longer exhalations. ${ }^{48-50}$ We suppose that a smaller lowering of the diaphragm in patients with COPD keeps the diameters of the crura and of the esophagus wider, favoring the presence of GERD.

\section{Not all patients with a respiratory pathology suffer from GERD}

This is probably due to the presence of some muscular components of the diaphragm, which are not noticed always: the muscle of Low and the transverse intertendinous muscle. The first one, of maximum width $15 \mathrm{~mm}$, originates from the left medial area of the left pillar. It goes toward the upper fibers of the right pillar, passing behind the esophageal crura; going forward, it crosses the fibers of the crura on the right, touching the hiatus of the vena cava and fusing with the fibers that constitute the crura itself, in the upper part. ${ }^{51}$ It is another small " 8 " that starts from the left lumbar area.

Behind the muscle of Low, the transverse intertendinous muscle links the two sides of the crura inferiorly and posteriorly. ${ }^{51}$
During normal inhalation, when the crura become horizontal and wider, just like the esophageal diameter, these two muscles contract, narrowing the inferior esophageal lumen. ${ }^{51}$ We suppose that the presence of these components of the diaphragm, despite its flatter and more horizontal position, makes it possible to manage the reflux better. We have no data about this.

The crural area of the diaphragm is less toned in patients with GERD than in individuals without GERD. ${ }^{52}$ We suppose that another cause of the presence of chronic reflux in patients with COPD is a diminished crural muscle tone, which does not guarantee an efficient anti-reflux barrier. ${ }^{53}$

Other structures that play a role in managing the reflux are the phrenoesophageal ligaments or the phrenoesophageal membrane or the membrane of Laimer. The LES, located inside the diaphragmatic esophageal hiatus, and the diaphragmatic crura (that surround the LES) represent the intrinsic and extrinsic sphincters, respectively; they are anatomically superimposable and firmly attached to one another through the phrenoesophageal ligaments. ${ }^{54}$

This very thin membrane (1 or $2 \mathrm{~mm}$ ) on the diaphragm is the continuation of the transverse fascia, which fuses with the endothoracic fascia and acts as a bridge between the crura and the esophageal wall (tunica externa and submucosa of the esophagus); under the diaphragm, it is located between the crura and the esophagus (esophageal tunica), and it reaches the angle of His..$^{55}$

The membrane is richly innervated and vascularized, and it contains plenty of lymphatic vessels; it is an elastic tissue with smooth muscular cells, fibroblasts and elastin. ${ }^{55}$ There is a hypothesis that this membrane can act as an elastic brake for the repositioning of the esophagus with breathing, thanks to its elastic hysteresis, helping to manage the anti-reflux barrier..$^{55}$ The membrane is innervated by the vagus nerve which, from the elastic tissue, sends mechanical afferences on the distortion that the external and internal sphincters endure. ${ }^{56}$ There is a triangular space between the esophagus and the crura (paraesophageal space); it is known that hyperinflation alters the natural position of the crura, probably shifting the esophagus upward with translation toward the left (exploiting this space), compromising the function of the phrenoesophageal membrane. ${ }^{11}$ This scenario could alter the vagal afferences, which follow the same afferences of the respiratory tract and then converge and reach the solitary nucleus in the medulla oblungata. ${ }^{11,57}$ This afferential alteration could increase the tone of the fascial membrane (through cholinergic routes). ${ }^{58}$ A closed circuit of non-physiological afferences would form. These afferences 
would continuously disturb the functional balance between the two sphincters (esophagus and diaphragm).

It is also important to consider the relation between the duodenum and the diaphragm. There is not enough data on the duodenal function and the presence of GERD in COPD.

A muscle stripe coming from the diaphragm, called Hilfsmuskel muscle, moves from the inferior area of the diaphragmatic crura to the arterial celiac trunk or to the superior mesenteric artery, with a close relation to the retropancreatic fascia or the Treitz's fascia; the latter leans in the upper part on the duodenum. ${ }^{59,60}$ This muscle stripe is innervated by the phrenic nerve. ${ }^{60}$ With a bridge of connective tissue, it fuses with the ligament of Treitz or suspensory muscle of duodenum near the arterial celiac trunk or the mesenteric artery. ${ }^{60}$ The triangle-shaped ligament of Treitz originates from the duodenum or from the duodenojejunal flexure. ${ }^{58,60}$ Unlike the Hilfsmuskel muscle, made up of contractile fibers, the ligament of Treitz has a strong component of smooth musculature. ${ }^{60}$

The Hilfsmuskel muscle contrasts the traction of the ligament of Treitz, while the latter has the task of keeping both the small intestine and the $\mathrm{C}$-shape of the duodenum in place. ${ }^{60,61}$ An alteration of the tensional balance between the two muscles could be a contributory cause of the reduction in blood provision to the diaphragm, demonstrated by the increase in oxidation and by the fall in pressure of microvascular oxygen $\left(\mathrm{PO}_{2}\right) \cdot{ }^{62,63}$ It could also increase the esophageal reflux, because the tensional alteration of the balance between the two muscles could determine an increase of the duodenal kinesia with hypersecretion, like it happens in patients with GERD. This would determine a reflux coming from the stomach and the duodenum. ${ }^{64}$ The ligament of Treitz is innervated by the sympathetic celiac and superior mesenteric plexus. ${ }^{60}$ Its traction, caused by the flattening of the diaphragm, could create a dyskinesia of the esophagus caused by altered shared (esophagus and ligament of Treitz) sympathetic afferences. ${ }^{65}$ We do not have enough data to substantiate these hypotheses.

An important element that deserves attention is the fascial system that involves the diaphragm, the esophagus and the lungs. The fascial continuum has many properties, for example, it can organize the mechanical tensions of all the body districts, viscera included, influencing their functional expression. ${ }^{66-68}$ The respiratory diaphragm not only affects the biochemical expression of the body, but, through the fascial system, also influences faraway anatomic areas with its behavior, as already explained in previous reports. ${ }^{69,70}$
The diaphragm acts as a bridge between the endothoracic fascia in the upper part and the transverse fascia in the lower part. ${ }^{69,70}$ It is known that, in the presence of COPD, the pulmonary parenchyma loses its elasticity and elastic hysteresis, becoming fibrous and stiffer, influencing negatively the elastic behavior of the pleurae..$^{71}$ The parietal pleura is covered by the endothoracic fascia, which fuses with the diaphragm and the phrenoesophageal ligaments. ${ }^{55}$ The diaphragm suffers from lung stiffening, flattening and changing its physiological position, with probable mechanical sub-diaphragmatic fascial tension that has repercussions on the transverse fascia and the phrenoesophageal ligaments.

The esophagus itself is fascially attached to the diaphragm and to the pleurae, not only to allow better movement among different districts but also to preserve its own positional identity. $^{72,73}$

It is known that when the phrenoesophageal ligaments lose their elasticity, for example, with aging or in the presence of a hiatal hernia, they change their intrinsic structure (fibrillar disorganization, infiltration of adipose cells) and become longer, thinner and more fragile, finally losing their function. $^{74}$

We suppose that the presence of GERD is also related to a mechanical alteration of the fascial system, caused by pulmonary fibrosis, which has negative effects on the function of the ligaments and on the behavior of the esophagus.

GERD is a systemic pathology and, as such, it must not be treated locally only. When a disease becomes systemic, other diseases appear, making the patient difficult to manage. In these cases, the collaboration of different specialists is fundamental for the clinical approach to the patient.

\section{Diaphragm, LBP and new considerations}

When the diaphragm lowers during the respiratory act, the fibers shorten and pull caudally the central connective area, expanding the thorax like a piston; the domes lower, pushing the viscera downward and raising the abdominal pressure. ${ }^{34}$ The high pressure created forces the last ribs to rotate outward, increasing the lateral expansion of the ribcage; the rotation allows an increase of the muscular tension and a better elastic hysteresis during exhalation. ${ }^{34,75}$ The abdominal pressure during inhalation creates a "sleeve" that tightens around the lumbar spinal area, stabilizing the spine and diminishing the electrical intervention of the spinal musculature. ${ }^{76}$ In patients with COPD, this happens to a smaller extent because of the flattening of the diaphragm and of its expiratory attitude; the muscle lowers at a lesser percentage (creating less abdominal pressure) and 
there is less contractile proprioceptive control. ${ }^{76}$ Normally, the increased abdominal pressure is compensated by the decreased pulmonary pressure; in patients with COPD, there is an increase of lung volumes and reduced abdominal pressure. ${ }^{76,77}$ This pathologic mechanism causes increase in lumbar lordosis. ${ }^{77}$

Considering what has been described up to now, we may suppose that an alteration of the lumbar structure and biomechanics is able to alter the function of the diaphragmatic pillars. With the diaphragm in exhalation position and the lumbar arch more accentuated, there could be a constant strain of the pillars, causing loss of their function (diminished muscle mass and proprioception).

Not only would the problem of LPB worsen, but, probably, a positional and functional malfunction of the pillars could also worsen or determine the problem of the reflux.

Lumbar hyperlordosis causes a decrease of $\sim 20 \%$ of the sliding of the different dorsolumbar fascial layers in patients with LBP. ${ }^{78}$ This decreased tissue excursion creates the conditions for the increase in fascial nociceptive afferences in higher percentage in comparison with the decreased/altered movement of the local muscles. ${ }^{78}$ The fascial structures become more sensitive to mechanical stimuli and, after a few days of local inflammation, they are able to generate an action potential similar to the initial stimulus causing the dysfunction; this potential can have an anterograde and retrograde propagation, causing inflammation at the extremities of the neural tract, such as in the spinal cord and in the innervated tissues. This mechanism is called ectopic electrogenesis. ${ }^{79}$ We suppose that LBP in patients with COPD is also caused by the fascial system, despite not having any data that can substantiate this statement.

When one takes charge of a patient, they must consider not only the pulmonary pathology but also, as a routine, different comorbidities, such as GERD and LBP, and evaluation of all the diaphragmatic components. This, in a multidisciplinary approach, could turn out to be a more efficient therapeutic approach.

LBP is a pathologic condition and not just a symptom. From what is described in the report, it is evident that diaphragm is an important muscle and can become the keystone for rehabilitation and understanding this problem.

\section{Conclusion}

COPD is a systemic pathology characterized by the presence of comorbidity. This study analyzed the causes of GERD and LBP recognized by scientific literature. The text took into consideration other mechanisms that could cause reflux and lumbar pain, making hypotheses of different clinical scenarios emphasizing the functions of the diaphragm. These observations are based on the functions and anatomic characteristics of the respiratory diaphragm which are not always considered.

The authors have tried to bring evidence from other scientific disciplines (gastroenterology, biomechanics and anatomy) on the causes of GERD and LBP in the presence of diaphragmatic dysfunction. An alteration of the diaphragm is present in COPD pathology. This is the first study that tries to combine pneumological knowledge with other scientific disciplines.

From this analysis, it could be possible to deduce useful elements to better comprehend the symptomatology status of the patient, finally improving the therapeutic approach in a multidisciplinary context.

\section{Disclosure}

The authors report no conflicts of interest in this work.

\section{References}

1. Westerik JA, Metting EI, van Boven JF, Tiersma W, Kocks JW, Schermer TR. Associations between chronic comorbidity and exacerbation risk in primary care patients with COPD. Respir Res. 2017; 18(1):31.

2. Chen YW, Camp PG, Coxson HO, et al. Comorbidities that cause pain and the contributors to pain in individuals with chronic obstructive pulmonary disease. Arch Phys Med Rehabil. 2017;98(8):1535-1543.

3. Smith MC, Wrobel JP. Epidemiology and clinical impact of major comorbidities in patients with COPD. Int J Chron Obstruct Pulmon Dis. 2014;9:871-888.

4. Shimizu Y, Dobashi K, Kusano M, Mori M. Different gastoroesophageal reflux symptoms of middle-aged to elderly asthma and chronic obstructive pulmonary disease (COPD) patients. J Clin Biochem Nutr. 2012;50(2):169-175.

5. Beeckmans N, Vermeersch A, Lysens R, et al. The presence of respiratory disorders in individuals with low back pain: a systematic review. Man Ther. 2016;26:77-86.

6. Kahrilas PJ, Lee TJ. Pathophysiology of gastroesophageal reflux disease. Thorac Surg Clin. 2005;15(3):323-333.

7. Boeckxstaens GE, Rohof WO. Pathophysiology of gastroesophageal reflux disease. Gastroenterol Clin North Am. 2014;43(1):15-25.

8. Pomari C, Mauroner L, Paiano S, et al. Bronchial reacutization and gastroesophageal reflux: is there a potential clinical correlation? Ann Transl Med. 2016;4(16):304.

9. Lin YH, Tsai CL, Chien LN, Chiou HY, Jeng C. Newly diagnosed gastroesophageal reflux disease increased the risk of acute exacerbation of chronic obstructive pulmonary disease during the first year following diagnosis - a nationwide population-based cohort study. Int J Clin Pract. 2015;69(3):350-357.

10. Lee AL, Button BM, Denehy L, et al. Exhaled breath condensate pepsin: potential noninvasive test for gastroesophageal reflux in COPD and bronchiectasis. Respir Care. 2015;60(2):244-250.

11. Houghton LA, Lee AS, Badri H, DeVault KR, Smith JA. Respiratory disease and the esophagus: reflux, reflexes and microaspiration. Nat Rev Gastroenterol Hepatol. 2016;13(8):445-460.

12. Rascon-Aguilar IE, Pamer M, Wludyka P, Cury J, Vega KJ. Poorly treated or unrecognized GERD reduces quality of life in patients with COPD. Dig Dis Sci. 2011;56(7):1976-1980. 
13. Del Grande LM, Herbella FA, Bigatao AM, Jardim JR, Patti MG. Inhaled beta agonist bronchodilator does not affect trans-diaphragmatic pressure gradient but decreases lower esophageal sphincter retention pressure in patients with Chronic Obstructive Pulmonary Disease (COPD) and Gastroesophageal Reflux Disease (GERD). J Gastrointest Surg. 2016;20(10):1679-1682.

14. Violante FS, Mattioli S, Bonfiglioli R. Low-back pain. Handb Clin Neurol. 2015;131:397-410.

15. Sribastav SS, Peiheng H, Jun L, et al. Interplay among pain intensity, sleep disturbance and emotion in patients with non-specific low back pain. PeerJ. 2017;5:e3282.

16. Bordoni B, Marelli F. Failed back surgery syndrome: review and new hypotheses. J Pain Res. 2016;9:17-22.

17. King HH. Addition of osteopathic visceral manipulation to OMT for low back pain decreases pain and increases quality of life. $J \mathrm{Am}$ Osteopath Assoc. 2017;117(5):333-334.

18. Tamer S, Öz M, Ülger Ö. The effect of visceral osteopathic manual therapy applications on pain, quality of life and function in patients with chronic nonspecific low back pain. J Back Musculoskelet Rehabil. 2017;30(3):419-425.

19. Critchley HD, Harrison NA. Visceral influences on brain and behavior. Neuron. 2013;77(4):624-638.

20. Giamberardino MA, Affaitati G, Lerza R, Lapenna D, Costantini R, Vecchiet L. Relationship between pain symptoms and referred sensory and trophic changes in patients with gallbladder pathology. Pain. 2005; 114(1-2):239-249.

21. Koganezawa T, Shimomura Y, Terui N. The role of the RVLM neurons in the viscero-sympathetic reflex: a mini review. Auton Neurosci. 2008;142(1-2):17-19.

22. Petersen T, Laslett M, Juhl C. Clinical classification in low back pain: best-evidence diagnostic rules based on systematic reviews. $B M C$ Musculoskelet Disord. 2017;18(1):188.

23. Bordoni B, Zanier E. Skin, fascias, and scars: symptoms and systemic connections. J Multidiscip Healthc. 2013;7:11-24.

24. Franke H, Franke JD, Fryer G. Osteopathic manipulative treatment for nonspecific low back pain: a systematic review and meta-analysis. BMC Musculoskelet Disord. 2014;15:286.

25. van Dam van Isselt EF, Groenewegen-Sipkema KH, Spruit-van Eijk M, et al. Pain in patients with COPD: a systematic review and metaanalysis. BMJ Open. 2014;4(9):e005898.

26. Sheng S, Zhenzhong S, Weimin J, Yimeng W, Qudong Y, Jinhui S. Improvement in Pulmonary Function of Chronic Obstructive Pulmonary Disease (COPD) Patients With Osteoporotic Vertebral Compression Fractures (OVCFs) After Kyphoplasty Under Local Anesthesia. Int Surg. 2015;100(3):503-509.

27. Masala S, Magrini A, Taglieri A, et al. Chronic obstructive pulmonary disease (COPD) patients with osteoporotic vertebral compression fractures (OVCFs): improvement of pulmonary function after percutaneous vertebroplasty (VTP). Eur Radiol. 2014;24(7):1577-1585.

28. HajGhanbari B, Holsti L, Road JD, Darlene Reid W. Pain in people with chronic obstructive pulmonary disease (COPD). Respir Med.2012; 106(7):998-1005.

29. HajGhanbari B, Garland SJ, Road JD, Reid WD. Pain and physical performance in people with COPD. Respir Med. 2013;107(11):1692-1699.

30. Smith MD, Chang AT, Seale HE, Walsh JR, Hodges PW. Balance is impaired in people with chronic obstructive pulmonary disease. Gait Posture. 2010;31(4):456-460.

31. Synnot A, Williams M. Low back pain in individuals with chronic airflow limitation and their partners - a preliminary prevalence study. Physiother Res Int. 2002;7(4):215-227.

32. Walsh LJ, Wong CA, Oborne J, et al. Adverse effects of oral corticosteroids in relation to dose in patients with lung disease. Thorax. 2001; 56(4):279-284.

33. LaBan MM, Kucway EJ. Aeolus myth: chronic obstructive lung disease and nocturnal lumbosacral pain in association with lumbar spinal stenosis and pulmonary hypertension. Am J Phys Med Rehabil. 2003;82(9):660-664.
34. Anraku M, Shargall Y. Surgical conditions of the diaphragm: anatomy and physiology. Surgical conditions of the diaphragm: anatomy and physiology. Thorac Surg Clin. 2009;19(4):419-429.

35. Mantilla CB, Sieck GC. Key aspects of phrenic motoneuron and diaphragm muscle development during the perinatal period. J Appl Physiol (1985). 2008;104(6):1818-1827.

36. Maish M. The diaphragm. Surg Clin North Am. 2010;90(5):955-968.

37. Greer JJ, Allan DW, Martin-Caraballo M, Lemke RP. An overview of phrenic nerve and diaphragm muscle development in the perinatal rat. J Appl Physiol (1985). 1999;86(3):779-786.

38. Allan DW, Greer JJ. Embryogenesis of the phrenic nerve and diaphragm in the fetal rat. J Comp Neurol. 1997;382(4):459-468.

39. Machado CB, Kanning KC, Kreis P, et al. Reconstruction of phrenic neuron identity in embryonic stem cell-derived motor neurons. Development. 2014;141(4):784-794.

40. Niedringhaus M, Jackson PG, Evans SR, Verbalis JG, Gillis RA, Sahibzada N. Dorsal motor nucleus of the vagus: a site for evoking simultaneous changes in crural diaphragm activity, lower esophageal sphincter pressure, and fundus tone. Am J Physiol Regul Integr Comp Physiol. 2008;294(1):R121-R131.

41. Niedringhaus M, Jackson PG, Pearson R, et al. Brainstem sites controlling the lower esophageal sphincter and crural diaphragm in the ferret: a neuroanatomical study. Auton Neurosci. 2008;144(1-2):50-60.

42. Young RL, Page AJ, Cooper NJ, Frisby CL, Blackshaw LA. Sensory and motor innervation of the crural diaphragm by the vagus nerves. Gastroenterology. 2010;138(3):1091-1101.e1-e5.

43. Kuo BR, Erickson CA. Vagal neural crest cell migratory behavior: a transition between the cranial and trunk crest. Dev Dyn. 2011;240(9): 2084-2100.

44. Pickering M, Jones JF. The diaphragm: two physiological muscles in one. J Anat. 2002;201(4):305-312.

45. Shafik A, Shafik I, El-Sibai O, Mostafa RM. Does the crural diaphragm share in the contractile activity of the costal diaphragm? The concept of an "autonomous esophageal crus" and its role in esophageal competence. Med Sci Monit. 2004;10(8):BR268-BR272.

46. Costa MM, Pires-Neto MA. Anatomical investigation of the esophageal and aortic hiatuses: physiologic, clinical and surgical considerations. Anat Sci Int. 2004;79(1):21-31.

47. Dianbo C, Wei L, Bolduc JP, Deslauriers J. Correlative anatomy of the diaphragm. Thorac Surg Clin. 2011;21(2):281-287.

48. Bordoni B, Marelli F, Morabito B, Sacconi B. Manual evaluation of the diaphragm muscle. Int J Chron Obstruct Pulmon Dis. 2016;11: 1949-1956.

49. Yamada Y, Ueyama M, Abe T, et al. Difference in diaphragmatic motion during tidal breathing in a standing position between COPD patients and normal subjects: time-resolved quantitative evaluation using dynamic chest radiography with flat panel detector system ("dynamic X-ray phrenicography"). Eur J Radiol. 2017;87:76-82.

50. Salito C, Luoni E, Aliverti A. Alterations of diaphragm and rib cage morphometry in severe COPD patients by CT analysis. Conf Proc IEEE Eng Med Biol Soc. 2015;2015:6390-6393.

51. Downey R. Anatomy of the normal diaphragm. Thorac Surg Clin. 2011;21(2):273-279.

52. Loukas M, Wartmann ChT, Tubbs RS, et al. Morphologic variation of the diaphragmatic crura: a correlation with pathologic processes of the esophageal hiatus? Folia Morphol (Warsz). 2008;67(4):273-279.

53. Kahrilas PJ. Anatomy and physiology of the gastroesophageal junction. Gastroenterol Clin North Am. 1997;26(3):467-486.

54. da Silva RC, de Sá CC, Pascual-Vaca ÁO, et al. Increase of lower esophageal sphincter pressure after osteopathic intervention on the diaphragm in patients with gastroesophageal reflux. Dis Esophagus. 2013;26(5):451-456.

55. Kwok H, Marriz Y, Al-Ali S, Windsor JA. Phrenoesophageal ligament re-visited. Clin Anat. 1999;12(3):164-170.

56. Young RL, Page AJ, Cooper NJ, Frisby CL, Blackshaw LA. Sensory and motor innervation of the crural diaphragm by the vagus nerves. Gastroenterology. 2010;138(3):1091-1101. 
57. Linz D, Hohl M, Vollmar J, Ukena C, Mahfoud F, Böhm M. Atrial fibrillation and gastroesophageal reflux disease: the cardiogastric interaction. Europace. 2017;19(1):16-20.

58. Undem BJ, Kollarik M. The role of vagal afferent nerves in chronic obstructive pulmonary disease. Proc Am Thorac Soc. 2005;2(4): 355-360.

59. Yang JD, Ishikawa K, Hwang HP, et al. Morphology of the ligament of Treitz likely depends on its fetal topographical relationship with the left adrenal gland and liver caudate lobe as well as the developing lymphatic tissues: a histological study using human fetuses. Surg Radiol Anat. 2013;35(1):25-38.

60. Jit I, Grewal SS. The suspensory muscle of the duodenum and its nerve supply. J Anat. 1977;123(Pt 2):397-405.

61. Masoud G, Hossain S, Bahman R, Zeinab K, Fatemeh A. New look at about nature, structure and function of Trietz ligament. Adv Biomed Res. 2014;3:69.

62. Scheibe N, Sosnowski N, Pinkhasik A, Vonderbank S, Bastian A. Sonographic evaluation of diaphragmatic dysfunction in COPD patients. Int J Chron Obstruct Pulmon Dis. 2015;10:1925-1930.

63. Poole DC, Kindig CA, Behnke BJ. Effects of emphysema on diaphragm microvascular oxygen pressure. Am J Respir Crit Care Med. 2001; 163(5):1081-1086.

64. Dzhulay GS, Sekareva EV. [Gastric and duodenal secretory and motorevacuatory activity in patients with gastroesophageal reflux disease associated with different types of reflux]. Ter Arkh. 2016;88(2):16-20. Russian.

65. Spencer NJ, Zagorodnyuk V, Brookes SJ, Hibberd T. Spinal afferent nerve endings in visceral organs: recent advances. Am J Physiol Gastrointest Liver Physiol. 2016;311(6):G1056-G1063.

66. Bordoni B, Marelli F. [Emotions in motion: myofascial interoception]. Complement Med Res. 2017;24(2):110-113. German.

67. Bordoni B, Marelli F. The fascial system and exercise intolerance in patients with chronic heart failure: hypothesis of osteopathic treatment. J Multidiscip Healthc. 2015;8:489-494.

68. Bordoni B, Zanier E. Clinical and symptomatological reflections: the fascial system. J Multidiscip Healthc. 2014;7:401-411.
69. Bordoni B, Zanier E. The continuity of the body: hypothesis of treatment of the five diaphragms. J Altern Complement Med. 2015; 21(4):237-242.

70. Bordoni B, Zanier E. Anatomic connections of the diaphragm: influence of respiration on the body system. J Multidiscip Healthc. 2013;6: 281-291.

71. Burgess JK, Mauad T, Tjin G, Karlsson JC, Westergren-Thorsson G. The extracellular matrix - the under-recognized element in lung disease? J Pathol. 2016;240(4):397-409.

72. Weijs TJ, Goense L, van Rossum PS, et al. The peri-esophageal connective tissue layers and related compartments: visualization by histology and magnetic resonance imaging. J Anat. 2017;230(2):262-271.

73. Stecco C, Sfriso MM, Porzionato A, et al. Microscopic anatomy of the visceral fasciae. J Anat. 2017;231(1):121-128.

74. Apaydin N, Uz A, Evirgen O, Loukas M, Tubbs RS, Elhan A. The phrenico-esophageal ligament: an anatomical study. Surg Radiol Anat. 2008;30(1):29-36.

75. Vostatek P, Novák D, Rychnovský T, Rychnovská S. Diaphragm postural function analysis using magnetic resonance imaging. PLoS One. 2013;8(3):e56724.

76. Janssens L, Brumagne S, McConnell AK, Hermans G, Troosters T, Gayan-Ramirez G. Greater diaphragm fatigability in individuals with recurrent low back pain. Respir Physiol Neurobiol. 2013;188(2): 119-123.

77. Kolar P, Sulc J, Kyncl M, et al. Postural function of the diaphragm in persons with and without chronic low back pain. J Orthop Sports Phys Ther. 2012;42(4):352-362.

78. Wilke J, Schleip R, Klingler W, Stecco C. The lumbodorsal fascia as a potential source of low back pain: a narrative review. Biomed Res Int. 2017;2017:5349620.

79. Bordoni B, Marelli F, Morabito B, Sacconi B. Depression, anxiety and chronic pain in patients with chronic obstructive pulmonary disease: the influence of breath. Monaldi Arch Chest Dis. 2017;87(1):811.
International Journal of COPD

\section{Publish your work in this journal}

The International Journal of COPD is an international, peer-reviewed journal of therapeutics and pharmacology focusing on concise rapid reporting of clinical studies and reviews in COPD. Special focus is given to the pathophysiological processes underlying the disease, intervention programs, patient focused education, and self management protocols.

\section{Dovepress}

This journal is indexed on PubMed Central, MedLine and CAS. The manuscript management system is completely online and includes a very quick and fair peer-review system, which is all easy to use. Visit http://www.dovepress.com/testimonials.php to read real quotes from published authors. 